the watching during the night-it was all night work if in the term night we include the dawn-could be done in the shelter itself, and this could be managed if the entrance to it was aligned on the part of the horizon to be chiefly watched.

Now what were those points? The circles supply the information. They were chiefly, as the May-year was then paramount, the sunrise place in May and August, when the sun's declination is $16^{\circ} 20^{\prime} \mathrm{N}$., and that in November and February, when the sun's declination is $16^{\circ} 20^{\prime} \mathrm{S}$, , these two sunrise places marking off the quarters of the year and the chief festivals. Next came the rising place of the clock-star, and later the place of sunrise on the longest and shortest days-the solstices.

The question to be settled, then, is, Do the entrances to the cromlechs point in these directions? Could the priests have done their night work under shelter?

Some of the data used in the attempt to answer this question I have obtained myself from the monuments; in other cases I have endeavoured to get the required information from the so-called plans or surveys to be found in archæological records. The great majority of these, however, I have found to be utterly useless for my purpose. A brilliant exception, however, is found in the carefully oriented work of Lukis on the Cornish monuments, so I will begin with Cornwall and the May-year sunrises.

The following table gives the theoretical values of the azimuths of the sunrise places. It has been previously shown in my book, "Stonehenge," that the circles conform to them.

Cornwall. Lat. $50^{\circ}$.

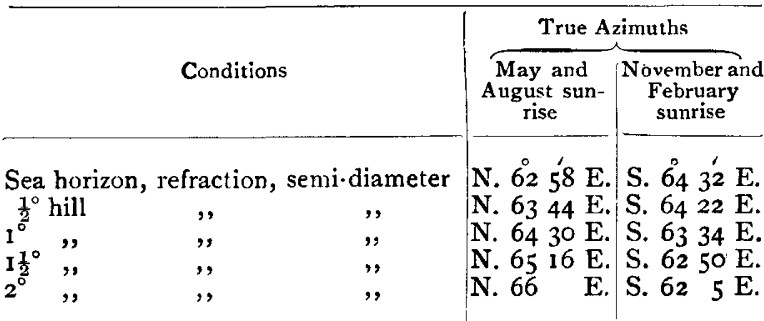

Following this table I give another, showing the azimuths of most of the chief Cornish cromlechs.

Orientation of Cornish Cromlechs.

\begin{tabular}{|c|c|c|}
\hline Name & Remarks & Azimuths (true) \\
\hline $\begin{array}{c}\text { SERIES I } \\
\text { Lesquoit Farm }\end{array}$ & My own observations, April, & $\mathrm{N} 64 \mathrm{E}$ \\
\hline Druid's Altar ... & $\begin{array}{l}\text { My own observations, April, } \\
\text { I907, at Pawton. Hill, } 1_{2}^{\circ}\end{array}$ & N. 64 E. \\
\hline Lanyon Quoit... & $\begin{array}{l}\text { This was "re-erected " before } \\
\text { Lukis's time, soI have taken } \\
\text { Borlase ("Antiquities of } \\
\text { Cornwall," plate xxi), as- } \\
\text { suming his N. is N. true ... }\end{array}$ & N. $66 \mathrm{E}$. \\
\hline Mulfra Quoit ... & Lukis, plate $\mathrm{xix} \quad \ldots \quad \ldots \quad \ldots$ & N. 63 E. \\
\hline $\begin{array}{l}\text { Chywoone Quoit } \\
\text { Zennor Quoit ... }\end{array}$ & 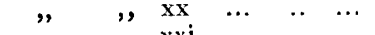 & N. $64 \mathrm{E}$. \\
\hline $\begin{array}{l}\text { Zennor Quoit ... } \\
\text { Three Brothers }\end{array}$ & 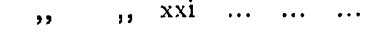 & N. 64 E. \\
\hline of Grugith ... & 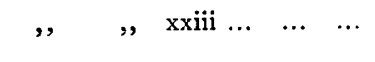 & N. 64 E. \\
\hline $\begin{array}{l}\text { SERIES } 2 \\
\text { Trewethy } \quad \ldots\end{array}$ & $\begin{array}{c}\text { My own observations, April, } \\
\text { I907, near St. Cleer ... ... }\end{array}$ & S. $62 \mathrm{E}$. \\
\hline Caerwynen & Lukis, plate xxiv $\ldots \quad \ldots \quad \ldots$ & S. $65 \mathrm{E}$. \\
\hline Pennance $\quad \cdots$ & $\begin{array}{llllll}\prime & \quad & \operatorname{xxix} & \ldots & \ldots & \ldots\end{array}$ & S. 64 E. \\
\hline
\end{tabular}

We see, then, that many of the chief Cornish cromlechs are aligned on the May and August or the November and February sunrises as carefully as are the outstanding stones connected with the associated circles.

The true azimuths have been determined from magnetic observations made by Lukis and myself by subtracting $20^{\circ} 30^{\prime}$, the west variation in Lukis's time, and $18^{\circ}$ at the present in the case of my own observations; it will be seen that they agree closely with the theoretical values given above.

The above list, however, does not exhaust all the cromlechs in Lukis's work perfect enough to allow of their orientation to be determined. We have :-

\begin{tabular}{|c|c|c|}
\hline Name & Remarks & Azimuths (true) \\
\hline Tregiffian $\ldots$ & Lukis, plate $\mathrm{xv} \ldots \quad \ldots \quad \ldots \quad \ldots$ & N. $\stackrel{\circ}{52} \mathrm{E}$. \\
\hline $\begin{array}{l}\text { Barrow near } \\
\text { Tregaseal cir- } \\
\text { cles } \quad \ldots \quad \ldots\end{array}$ & $\begin{array}{l}\{\text { Lukis, plate } x v i i, \text { reproducing } \\
\left\{\begin{array}{cccc}\text { Trounson... } & \ldots & \ldots & \ldots\end{array}\right\}\end{array}$ & S. $50 \mathrm{E}$. \\
\hline
\end{tabular}

These are solstitial alignments. The variation of $1^{\circ}$ or $2^{\circ}$ in this and the preceding table no doubt arises from the fact that the height of the horizon varies from place to place, and no information on this head is given by Lukis.

NORMan LOCKyer.

\section{THE PRESERVATION OF EGGS.}

FEW people not directly connected with the trade have any adequate idea of the extent to which the egg of the domestic fowl is imported into this country. Whether the volume of this trade ought to be an unmixed source of satisfaction to us is another question, for there can be little doubt that if some of the energy, enterprise, and organising power which have been turned to such excellent account in Denmark, for example, were applied to the production of eggs in this country, we should be less dependent than we are on foreign supplies. Intimately bound up with this question of egg production is that of their preservation, but although much has been written on the value of particular methods, no systematic investigation of the conditions under which eggs must be kept to maintain and ensure their quality as food has hitherto been attempted, nor has any proper comparison been made as to the relative merits of the various methods which are practised. Those who are interested in this important subject will therefore welcome the appearance of a paper by Mr. Fr. Prall in a recent number of the Zeitschrift für Untersuchung der Nahrungs- und Genussmittel (No. 7, vol. xiv., October I, I907, p. 445), in which the question is treated both observationally and experimentally with all the precision and care which should characterise a scientific inquiry.

The adequate solution of this problem demands that the eggs when preserved shall maintain their normal appearance, smell and taste; in other words, they must in nowise differ in chemical and physical characters, or in behaviour on cooking, from fresh eggs. The chemical and physical changes to which eggs are naturally subject are largely dependent on the temperature and relative humidity of the air, and on the presence in it of moulds and germs. In an absolutely sterile atmosphere at a sufficiently low temperature and of a proper degree of humidity, eggs will preserve their " freshness" for very long periods of time, if not indefinitely; and all successful methods of keeping eggs imply a practical recognition of these conditions.

Of the various methods of distinguishing old and 
bad eggs from fresh eggs, one of the simplest is to make a hole of about the size and shape of an egg in a wooden or tin box, and hold the egg in the inside of this box against the light behind the hole. Good sound eggs are thus seen to be perfectly transparent without striations or spots, and the bubble of air within is not wider in diameter than a sixpence.

Eggs selected for preserving should be those of well-fed fowls-preferably from those of which corn is the chief diet. The eggs should be quite clean; if dirty they should be washed with a little dilute alcohol (5o per cent.), and carefully dried.

In what may be called "dry conservation," the main thing is to keep the surrounding air as clean as possible, and free from smell. The temperature should be low, but should not sink much below $32^{\circ} \mathrm{F}$., otherwise freezing might cause the eggs to burst. The relative humidity should be from 60 to 80 . The best plan is to stand the eggs on an egg-rack in a cool, light cellar, and preferably in an ice closet, or. on the large scale, in cold-air stores, with their points downwards, so that the air can circulate freely round them. Nothing is gained by turning the eggs at short intervals, say weekly, as recommended by some; or by packing them in salt, sawdust, powdered coal, or charcoal, wood ashes, sand, \&c. Some of these things are found to "taint" the eggs; others are apt to become damp and set up the action of moulds.

It is occasionally recommended that the egg should be protected from the outer air by covering the shells with fat, vaseline, paraffin wax, collodion, \&c., or that the shell should be treated with salicylic, boracic, or hydrofluosilicic acid, or even sulphuric acid, whereby the calcareous material is chemically altered and made less pervious. Immersing the egg in Condy's fluid or a solution of potassium permanganate has also been suggested. Eggs so treated in no case were found to keep better than by cold storage in pure air.

Eggs which cannot be kept in cold stores or in an ice-chest may be preserved by Hanika's method. This consists in first putting the clean eggs into recentlyboiled water at a temperature of about $110^{\circ}$, and then dipping them into boiling water for ro seconds, after which they are to be immediately put into cold water By this treatment all organisms are killed, and a hard coating is formed between the shell and the "white." The shells are finally washed with a little strong alcohol, dried, and placed in clean, dry saw-dust. Eggs so treated were found to be in perfect condition after the lapse of nine months.

Attempts are frequently made to preserve eggs by immersing them in solutions of various salts, or of substances which are known to act as antiseptics. Few of these solutions give a wholly satisfactory result; indeed, many of them, as, for example, salt, salicylic acid, borax, and glycerin, penetrate the shell, and either harden the yolk or impair the flavour. Of these liquids lime-water has been most frequently used, but by long immersion in this solution the yolk is apt to mix with the white, and the shell is rendered so fragile that it is very liable to be broken on boiling. The white of an egg which has been kept in limewater is difficult to "whip." Much better results are obtained by the use of a ro per cent. solution of waterglass, especially if the shells are smeared with fat or vaseline, whereby the slight taste of the alkali which the eggs are otherwise apt to acquire may be obviated.

Mr. Prall's paper, which contains the results of many hundreds of experiments and carefully made observations, arranged in tabular form and set out in detail, is a valuable contribution to the economics of an important food problem, and merits careful study by those who are interested in the subject.

NO. I 987 , voL. 77$]$

\section{NOTES.}

ON Thursday last, November 21, the Lord Mayor of Liverpool presided over an influential gathering of Welshmen from that city and from the Principality, and the following resolution was carried unanimously :-_" That this meeting believes that the time has come for the early history of Wales to receive full and systematic investigation by all the means at the disposal of modern archæological science." The Oxford professor of Celtic (Sir John Rhys) supported this at some length, pointing out that sporadic excavations were not enough in themselves, and that a systematic survey should also be made of all the antiquities of Wales and the Marches. This would entail, not only the digging over of barrows and graves, but the orientation of stone circles, cromlechs, and camps. The theodolite as well as the shovel should be called into requisition; in fact, no means should be neglected which might tend to increase the value of the investigation. Two other motions were passed, and a committee, which includes Dr. Arthur J. Evans and Prof. Haverfield among its members, was appointed for the carrying out of the work. The weight of the undertaking will fall on the University of Liverpool, which, however, is to receive assistance from the Welsh colleges. Our readers need not be reminded that Liverpool University lays special stress on the study of archæology, and includes among its staff Prof. Bosanquet and Prof. John Garstang. We have every confidence that any work undertaken by Liverpool will be done well and thoroughly. The organising secretary is $\mathrm{Mr}$. Owen Rhoscomyl, 38 Bedford Street, Liverpool.

The Wilde medal for 1908 of the Manchester Literary and Philosophical Society has been awarded to Prof. J. Larmor, F.R.S., and will be presented to him on March 3 next. Prof. Larmor will on that date deliver the Wilde lecture on "The Physical Aspect of the Atomic Theory," and will be entertained afterwards at a dinner in his honour.

The Physical Society announces that the third annual exhibition of electrical, optical, and other physical apparatus will be held at the Royal College of Science, South Kensington, on Friday evening, December 13, from seven to ten o'clock.

THE executive committee of the National Physical Laboratory has appointed $\mathrm{Mr}$. G. W. Walker, official assistant to the professor of natural philosophy in the University of Glasgow, as superintendent of the Eskdalemuir Observatory. Mr. Guy Barr, of Christ's College, Cambridge, has been appointed to an assistantship in the metallurgical and chemical department of the National Physical Laboratory.

THE death is announced, at the age of sixty-nine, of Prof. T. Barker, professor of mathematics at Owens College, Manchester, from 1865 to 1885 .

AN international exhibition of applications of electricity will be opened at Marseilles on April 19, 1908, under the patronage of the Grovernment of the French Republic, and with the cooperation of the local authorities, municipal council, general council, Board of Trade, and other bodies. Particulars can be obtained at the office of the Commissariat-General, Boulevard Louis Salvator, 52, Marseilles, and at the Secretariat-General, $6_{3}$ Boulevard Haussmann, Paris.

The Times correspondent at Cape Town reports on November 23 that the Chief Justice, presiding at a meeting of the National Preservation Society, urged the need of stronger measures to preserve rare flora and fauna from 